\title{
可溶液加工蓝色聚集诱导发光小分子的合成及其器件性能
}

\author{
余韵 ${ }^{\dagger}$ 杨杰 ${ }^{\dagger}$ 任子淳谢国华* 李倩倩 李振* \\ (武汉大学 化学与分子科学学院 武汉 430072)
}

\begin{abstract}
摘要 利用四苯基甲烷中碳原子特殊的 $\mathrm{sp}^{3}$ 轨道杂化结构来打断并控制分子内共轭程度, 并采用硅原子替换四苯基甲 烷中的碳原子合成四苯基硅烷. 将这两种结构作为核, 在其四周以四苯乙烯(TPE)或三苯乙烯(triPE)修饰, 设计并合成 了六个具有聚集诱导发光(AIE)效应的小分子. 这些分子均可以溶解在常见有机溶剂中并具有良好的热稳定性. 通过溶 液旋涂法将其应用到有机电致发光器件(OLED)中, 得到最好的器件效率为亮度最大值 $\left(L_{\max }\right) 1730 \mathrm{~cd} \cdot \mathrm{m}^{-2}$, 电流效率最 大值 $\left(L_{\max }\right) 2.21 \mathrm{~cd} \cdot \mathrm{A}^{-1}$, 功率最大值 $\left(\eta_{\mathrm{p}, \text { max }}\right) 0.77 \mathrm{~lm} \cdot \mathrm{W}^{-1}$, 外量子效率最大值 $\left(\eta_{\mathrm{ext}, \text { max }}\right) 1.01 \%$.
\end{abstract}

关键词 聚集诱导发光; $\mathrm{sp}^{3}$ 轨道杂化; 有机电致发光; 溶液旋涂法

\section{Synthesis of Solution Processable Blue AIEgens and the Device Performance}

Yu, Yun ${ }^{\dagger} \quad$ Yang, Jie $^{\dagger} \quad$ Ren, Zichun Xie, Guohua* Li, Qianqian Li, Zhen*

(Department of Chemistry, Hubei Key Lab on Organic and Polymeric Opto-Electronic Materials, Wuhan University, Wuhan 430072)

\begin{abstract}
By utilizing the special $\mathrm{sp}^{3}$ hybridization of tetraphenylmethane to break and control the intramolecular conjugation, and using silicon atom to replace the carbon atom in tetraphenylsilane, six molecules of C-4pTPE, C- $4 m$ TPE, C-4triPE, Si- $4 p$ TPE, Si-4mTPE, and Si-4triPE, were designed and successfully obtained, with tetraphenylethylene (TPE) and triphenylethylene (triPE) introduced to the core of tetraphenylmethane or tetraphenylsilane as rotors. These six molecules all possess typical aggregation induced emission (AIE) properties, they are all nearly nonemissive when readily dissolved in pure THF, but with the water fraction increasing, the PL intensity gradually increased. Due to their good AIE properties and thermal stability, they were fabricated in OLED devices by the solution process conveniently, with the maximum luminance $\left(L_{\max }\right)$, maximum current efficiency $\left(\eta_{\mathrm{C}, \max }\right)$, maximum power efficiency $\left(\eta_{\mathrm{p}, \max }\right)$ and maximum external quantum efficiency $\left(\eta_{\text {ext,max }}\right)$ at $1730 \mathrm{~cd} \cdot \mathrm{m}^{-2}, 2.21 \mathrm{~cd} \cdot \mathrm{A}^{-1}, 0.77 \mathrm{~lm} \cdot \mathrm{W}^{-1}$ and $1.01 \%$, respectively.

Keywords aggregation induced emission; $\mathrm{sp}^{3}$ hybridization; OLED device; solution process
\end{abstract}

\section{Introduction}

Organic light-emitting diodes (OLEDs) have been a research focus for almost 30 years owing to their great applications in flat-panel displays, solid-state lighting and wearable electronics, since Tang's work in the late 1980s. ${ }^{[1 \sim 3]}$ Among different types of materials for high performance OLED devices, the good luminogens acting as emissive layers is generally considered as the key component, either in enhancing the performance of an OLED device or being helpful to simplify the device configuration and lower the construction costs. ${ }^{[4 \sim 8]}$

So far, a variety of luminogenic materials have been reported with good performance, however, most of them usually suffered from aggregation-caused quenching (ACQ): their good emission in solution are often greatly weakened or quenched at high concentration, owing to the formation of excimers or exciplexes in aggregated states. ${ }^{[9]}$ Thanks to the pioneer work of Ben Zhong Tang' group, the design of AIEgens with the characteristic of aggregation induced emission (AIE) has been proved to be an effective approach to tackle this ACQ problem. ${ }^{[10]}$ Nowadays, AIE has become a hot topic in the research field of advanced functional materials. ${ }^{[1]}$

On the other hand, in full-color displays, the highly efficient and stable blue emitters are badly needed, since the blue emitter can not only effectively reduce the power consumption of the devices but also be utilized to generate emission of other colors by energy transfer to a suitable emissive dopant. ${ }^{[12]}$ However, unlike their red and green counterparts with satisfactory performance, efficient and stable luminogens with standard blue or deep blue were still relatively rare, because of the intrinsic large bandgap and the encountered problems of stability. ${ }^{[13,14]}$ Thus, it is urgent to develop high efficient blue and deep blue luminescent materials. Among the typical AIE luminogens, tetraphenylethylene (TPE) and many of its derivatives like triphenylethylene (triPE) enjoy the advantages of facile

$\dagger$ Yun Yu and Jie Yang contributed equally to this paper.

*E-mail: lizhen@whu.edu.cn or lichemlab@163.com,xgh-008@163.com; Tel.: 027-68755363; Fax: 027-68756757

Received July 28, 2016; published August 24, 2016.

Supporting information for this article is available free of charge via the Internet at http://sioc-journal.cn.

Project supported by the National Fundamental Key Research Program (No. 2013CB834701) and the National Natural Science Foundation of China (Nos. 21325416, 51573140, 6715751469).

国家科技部 973 项目(No. 2013CB834701)和国家自然科学基金委项目(Nos. 21325416, 51573140, 6715751469). 
synthesis and outstanding AIE effects, but none of them is an efficient emitter in deep-blue region. Once some aromatic groups were introduced to enhance the LED performance of the designed AIEgens, their emissions are always red-shifted, departing from the required blue or deep-blue region. According to our previous works and the reported results of other groups, the unpleasant red-shift could be controlled in a large degree through changing the linkage mode, constructing more twisted configuration and decreasing the conjugated unit. ${ }^{[15]}$

Also, in the fabrication of the OLED device, there are two mainly approaches to obtain a good thin film of the organic emitting layer: vacuum deposition and solution process. In comparison with vacuum deposition, the solution process is generally accepted as a more feasible means to realize low-cost, large-area OLED displays or lighting products. But there are very few reports about spin coating of small molecules. Actually, in our previous works, we always used vacuum deposition in the fabrication of the OLED device. Thus, is it possible to develop some AIEgens applicable for the fabrication in solution process by spin coating?

Prompted by the above points, in this communication, we utilized the special $\mathrm{sp}^{3}$ hybridization of tetraphenylmethane to break and control the intramolecular conjugation, and used silicon atom to exchange carbon atom in tetraphenylmethane as tetraphenylsilane. Around the core of tetraphenylmethane or tetraphenylsilane, TPE and triPE were utilized as the rotors. Accordingly, six AIEgens, with their structures presented in Chart 1, were successfully obtained. C-4triPE, one of the six molecules was once synthesized by Wang et al. They coordinated the triPE units around a tetrahedral junction site, with the aim to minimize the tendency of conjugated organic fragments to crystallize. ${ }^{[16]}$ And really, these AIEgens synthesized by our group could be fabricated in OLED devices by the solution process conveniently, with a maximum luminance $\left(L_{\text {max }}\right)$ of $1730 \mathrm{~cd} \bullet \mathrm{m}^{-2}$, a maximum current efficiency $\left(\eta_{\mathrm{C} \text {,max }}\right)$ of $2.21 \mathrm{~cd} \cdot \mathrm{A}^{-1}$, a maximum power efficiency $\left(\eta_{\mathrm{p}, \text { max }}\right)$ of $0.77 \mathrm{~lm} \bullet \mathrm{W}^{-1}$, a maximum external quantum efficiency $\left(\eta_{\text {ext,max }}\right)$ of $1.01 \%$, respectively. Here, we would like to present their synthesis, characterization, theoretical calculation, and photophysical properties in detail.

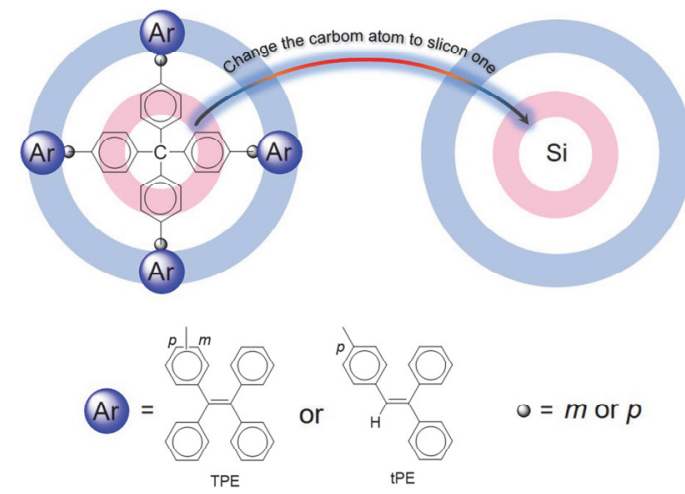

C-4triPE: Ar=triPE, $p$ C-4pTPE: $A r=T P E, p$ C-4mTPE:Ar=TPE, $m$

Si-4triPE: Ar=triPE, $p$ Si-4pTPE: Ar=TPE, $p$ Si-4mTPE: $A r=T P E, m$

Chart 1 Chemical structure of C-4pTPE, C-4mTPE, C-4triPE, Si-4pTPE, Si-4mTPE and Si-4triPE

\section{Results and discussion}

\subsection{Synthesis}

The six target AIEgens were successfully obtained through Suzuki cross-coupling reactions (the detailed procedures and characterization data are given in the supporting information) and they were all fully characterized by ${ }^{1} \mathrm{H}-\mathrm{NMR}$ and ${ }^{13} \mathrm{C}-\mathrm{NMR}$, mass spectrometry and elemental analysis.

\subsection{Thermal properties}

Thermogravimetric analysis (TGA) and differential scanning calorimetry (DSC) were used to investigate the thermal properties of these six AIEgens. Figure S3 shows that they were all thermally stable and the thermal decomposition temperatures $\left(T_{\mathrm{d}}\right.$, corresponding to $5 \%$ weight loss) were all higher than $380{ }^{\circ} \mathrm{C}$. C-4m TPE and Si-4pTPE have relatively high glass transition temperatures $\left(T_{\mathrm{g}}\right)$ as $142{ }^{\circ} \mathrm{C}$ and $137{ }^{\circ} \mathrm{C}$, respectively (Table 1). Unfortunately, the DSC curves of the other four molecules showed no obvious $T_{\mathrm{g}} \mathrm{s}$ (Figure $\mathrm{S} 4$ ). The high $T_{\mathrm{d}}$ values should be attributed to their large molecular weights. The high $T_{\mathrm{d}}$ and $T_{\mathrm{g}}$ indicate that these six molecules have excellent thermal and morphological stability, which can contribute to the fabrication of the homogeneous and stable amorphous emissive layer in OLED devices.

\subsection{AIE properties}

All of the six molecules are soluble in common organic solvents, such as THF, chloroform and toluene, but insoluble in water. Figure S6 in the Supporting Information shows the UV-vis absorption spectra of C-4pTPE, C-4 $m$ TPE, C-4triPE, Si-4pTPE, Si-4mTPE and Si-4triPE in THF. The UV-vis spectra of the molecules using tetraphenylmethane as core are correspondingly similar to the molecules with the tetraphenylsilane core, possibly due to the similar structure and conjugation lengths of tetraphenylmethane and tetraphenylsilane. The UV-vis spectra of C-4triPE and Si-4triPE are similar, with the maximum absorption wavelength $\left(\lambda_{\max }\right)$ at $333 \mathrm{~nm}$ and $331 \mathrm{~nm}$, respectively. The spectra of C-4pTPE and Si- $4 p$ TPE are almost the same, with $\left(\lambda_{\max }\right)$ at $326 \mathrm{~nm}$ and $327 \mathrm{~nm}$, respectively, a little blue-shifted in comparison with those of $\mathrm{C}-4$ triPE and Si-4triPE. That might be attributed to the shorter conjugation lengths of C-4triPE and Si-4triPE rather than C-4pTPE and Si-4pTPE, due to the absence of one phenyl from TPE to triPE. As for C-4mTPE and Si-4mTPE, they also have similar spectra with blue-shifted $\lambda_{\text {max }}$ at 314 and $315 \mathrm{~nm}$, respectively, suggesting that they possess lower conjugation. Due to the meta-position linkage mode, the conformation of C-4mTPE and Si- $4 m$ TPE should be more twisted between TPE and the tetraphenylmethane and tetraphenylsilane core, leading to their shorter effective conjugation lengths, as coupled with the bad conjugation effect also derived from the meta linkage mode. This confirmed the powerful control of the intramolecular conjugation by simply changing the linkage mode.

In order to investigate the AIE characteristics of these six luminogens, their fluorescent behaviors were studied. We chose THF as good solvent and water as poor solvent due to their miscibility. They are all nearly nonemissive when readily dissolved in pure THF, but with the water 
fraction increasing, the PL intensity gradually increased. The detail data including PL change and fluorescent images of the fluorophores in THF and THF/water mixtures are shown in the Figure S5 in the supporting information. Taking C-4mTPE as an example. Figure 1 clearly shows the PL change, fluorescent image and quantum yield in $\mathrm{THF}$ and $\mathrm{THF} /$ water mixtures. The PL curves of C-4mTPE is nearly a flat line coinciding to the abscissa when dissolved in pure THF, demonstrating the faint emission property in the solution state. And the PL intensity of $\mathrm{C}-4 m$ TPE remains low in aqueous mixtures with less than $50 \%$ water fraction but starts to increase swiftly afterwards. The emission intensity reaches its maximum at $95 \%$ water fraction. From pure THF solution to the THF/water mixture with $95 \%$ water content, the PL intensity rises by 105 -fold, which can also be verified by visual observations. When illuminated under $365 \mathrm{~nm}$ UV lamp, its THF solution emitted no observable light, but intense emission was clearly observed from the $\mathrm{THF} /$ water mixture with 95\% water content (Figure 1A). Similar phenomena are also observed for other molecules. Clearly, the emission is induced by the aggregate formation, confirming that they

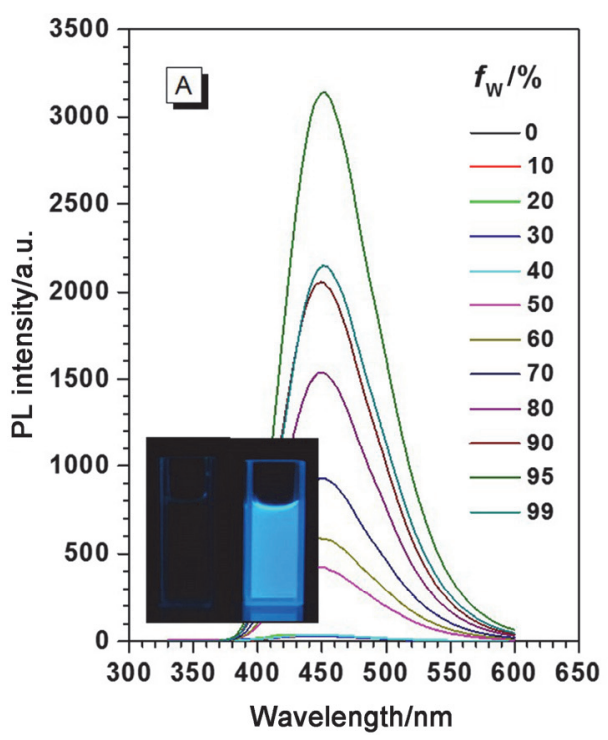

are AIE-active. In dilute solution, the rotation of multiple phenyl rings has consumed the energy of the excitons through the nonradiative relaxation channel and thus quenched the light emission of the dye molecules. In aggregate state, the intramolecular rotation is restricted, thus allowing the luminogens to emit intensely.

The solution-state fluorescence quantum yields $\left(\Phi_{\mathrm{F}, \mathrm{S}}\right)$ of C-4triPE, C-4pTPE, C-4mTPE, Si-4triPE, Si-4pTPE and Si-4mTPE estimated by using $0.1 \mathrm{~mol} / \mathrm{L}$ 9,10-diphenylanthrancene $\left(\Phi_{\mathrm{F}}=90 \%\right.$ in cyclohexane $)$ as reference are merely $0.30 \%, 0.10 \%, 0.10 \%, 0.10 \%, 0.080 \%$ and $0.20 \%$, respectively, indicating that they are all weak emitters in solution (Figure 1B). From pure solution in THF to the aggregated state in a $99 \%$ aqueous mixture, the fluorescence quantum yields $\left(\Phi_{\mathrm{F}}\right)$ of C-4triPE, C-4pTPE, C-4mTPE, Si-4triPE, Si- $4 p$ TPE and Si-4mTPE increased up to $46 \%, 63 \%, 26 \%, 36 \%, 36 \%$ and $17 \%$, respectively, once again proving they are all AIE-active. The $\Phi_{\mathrm{F}}$ of different solutions and aggregated state were calculated according to the previous literature. ${ }^{[17]}$

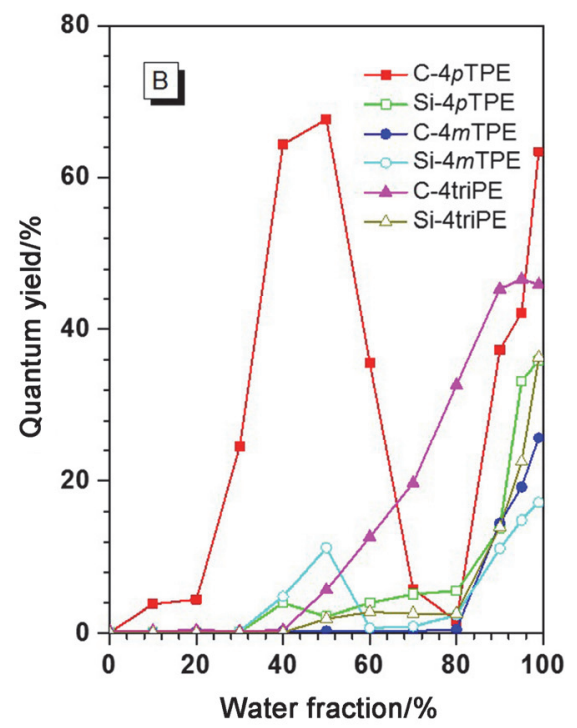

Figure 1 (A) PL spectra of $\mathrm{C}-4$ triPE in different $\mathrm{THF} / \mathrm{H}_{2} \mathrm{O}$ ratio $\left(f_{\mathrm{W}}=\right.$ water fraction). Inset: photos of $\mathrm{C}-4$ triPE in $\mathrm{THF} /$ water mixtures $\left(f_{\mathrm{W}}=0 \%\right.$ and $90 \%$ ) under UV lamp illumination. Concentration $=10 \mu \mathrm{mol} / \mathrm{L}$, excitation wavelength: $310 \mathrm{~nm}$. (B) Plots of fluorescence quantum yields of C-4pTPE, C-4mTPE, C-4triPE, Si-4pTPE, Si-4mTPE and Si-4triPE, determined in THF/ $\mathrm{H}_{2} \mathrm{O}$ solutions by using $9,10-$ diphenylanthracene $(\Phi=90 \%$ in cyclohexane) as standard versus water fractions

Table 1 The thermal, electrochemical and photophysical data of the luminogens

\begin{tabular}{|c|c|c|c|c|c|c|c|c|c|c|}
\hline & $T_{\mathrm{d}}^{a} /{ }^{\circ} \mathrm{C}$ & $T_{\mathrm{g}} /{ }^{\circ} \mathrm{C}$ & $E_{\mathrm{g}}^{b} / \mathrm{eV}$ & $E_{\mathrm{HOMO}}{ }^{c} / E_{\mathrm{LUMO}}{ }^{d}(\mathrm{eV})$ & $\lambda_{\mathrm{abs}}{ }^{e} / \mathrm{nm}$ & $\mathrm{PL} \lambda_{\max }($ film $) / \mathrm{nm}$ & $\Phi_{\mathrm{F}}($ solution $) / \%$ & $\mathrm{PL} \lambda_{\max }(\operatorname{aggr}) / \mathrm{nm}$ & $\Phi_{\mathrm{F}}(\mathrm{aggr}) / \%$ & $\alpha(\mathrm{AIE})^{g}$ \\
\hline C- $4 p$ TPE & 480 & - & 3.80 & $-5.57 /-1.77$ & 326 & 492 & 0.10 & 491 & 63 & 634 \\
\hline C-4m TPE & 494 & 142 & 3.95 & $-5.49 /-1.54$ & 314 & 465 & 0.10 & 469 & 26 & 257 \\
\hline C-4triPE & 496 & - & 3.72 & $-5.66 /-1.94$ & 333 & 448 & 0.30 & 451 & 46 & 135 \\
\hline $\mathrm{Si}-4 p \mathrm{TPE}$ & 471 & 137 & 3.79 & $-5.59 /-1.80$ & 327 & 487 & 0.080 & 490 & 36 & 449 \\
\hline $\mathrm{Si}-4 m \mathrm{TPE}$ & 500 & - & 3.94 & $-5.66 /-1.72$ & 315 & 464 & 0.20 & 469 & 17 & 85.9 \\
\hline Si-4triPE & 385 & - & 3.75 & $-5.70 /-1.95$ & 331 & 449 & 0.10 & 449 & 36 & 363 \\
\hline
\end{tabular}

${ }^{a} 5 \%$ weight loss temperature measured by TGA under $\mathrm{N}_{2} \cdot{ }^{b}$ Band gap estimated from optical absorption band edge of the solution. ${ }^{c}$ Calculated from the onset oxidation potentials of the compounds. ${ }^{d}$ Estimated using empirical equations $E_{\mathrm{LUMO}}=E_{\mathrm{HOMO}}+E_{\mathrm{g} .}{ }^{e}$ Observed from absorption spectra in dilute THF solution. ${ }^{f}$ Determined in $V(\mathrm{THF}): V\left(\mathrm{H}_{2} \mathrm{O}\right)=1: 99$ solution. ${ }^{g} \alpha_{\mathrm{AIE}}=\Phi_{\mathrm{F}}($ aggregation $) / \Phi_{\mathrm{F}}($ solution $)$. 
We further investigated the PL behaviors of the six AIEgens in the solid state. As shown in Figure S7, the emissions of their thin films are observed at 449 $492 \mathrm{~nm}$ in the blue region, similar to the PL as nanoparticles in $\mathrm{THF} /$ water mixtures (Table 1). However, the solid state emissions of C- $4 p$ TPE and Si- $4 p$ TPE are significantly red-shifted compared to those of C-4triPE, Si-4triPE, C-4mTPE and Si-4mTPE, with a PL peak at 492 and 487 $\mathrm{nm}$, indicating that $\mathrm{C}-4 p \mathrm{TPE}$ and $\mathrm{Si}-4 p \mathrm{TPE}$ are more conjugated than C-4triPE, Si-4triPE and C-4mTPE, Si-4mTPE, as the result of the decreased conjugation and the more twisted structure.

\subsection{Theoretical calculations}

To further understand the structure-property relationship at the molecular level, Density Functional Theory (DFT) calculations (B3LYP/6-31g*) of the six AIEgens were carried out to obtain their optimized structures and orbital distributions. As demonstrated in Figure S8, for C- $4 p$ TPE, the electron clouds of HOMO and LUMO energy levels are almost the same and mainly located on the two TPE branches. For Si-4pTPE, the HOMO is mainly located on the TPE moieties, while the LUMO is dispersed on the whole molecule. And for C-4mTPE and Si-4mTPE the HOMO and LUMO are both located on one TPE moiety of four sides. So the energy levels of C-4pTPE, C-4mTPE, $\mathrm{Si}-4 p \mathrm{TPE}$ and $\mathrm{Si}-4 m \mathrm{TPE}$ only partly overlapped, which might lead to intramolecular charge transfer (ICT) effects. And the molecular structures of these four molecules were highly twisted, which would weaken the ICT effect. For C-4triPE and Si-4triPE, the HOMO and LUMO are nearly distributed in average of the whole molecules, indicating that there was no intramolecular charge transfer (ICT). For those molecules, there were no regular distribution of the HOMO and LUMO electron clouds, leading to weak ICT effect. Thus, the nonpolar properties of these AIEgens partially ensured their blue emissions in their OLED devices.

\subsection{Electrochemical properties}

The electrochemical properties of C-4triPE, C-4pTPE, C-4 $m$ TPE, Si-4triPE, Si- $4 p$ TPE and Si-4mTPE were investigated by cyclic voltammetry (CV) (Figure S9). The HOMO energy levels were calculated to be 5.66, 5.57, $5.49,5.70,5.59$ and $5.60 \mathrm{eV}$, respectively, according to the following equation: $\mathrm{HOMO}=-\left(4.8-E_{(\mathrm{Fc} / \mathrm{Fc}+}+E_{\mathrm{ox}}\right) \mathrm{eV}$, suggesting that C-4mTPE might have the best hole-injection ability among the six AIEgens. Their LUMOs were obtained from the optical band gap energies as $1.94,1.77,1.54,1.95,1.80$ and $1.72 \mathrm{eV}$ for C-4triPE, C-4pTPE, C-4mTPE, Si-4triPE, Si-4pTPE and Si-4mTPE, respectively. Thus, $\mathrm{C}-4$ triPE and $\mathrm{Si}-4$ triPE had a better electronic injection capacity, which might contribute to their good performance in OLED devices. Furthermore, the higher band gap energies of C-4mTPE and Si-4m TPE (3.95 and $3.94 \mathrm{eV}$ ) have clearly demonstrated their shorter effective conjugation lengths, which is closely related to their twisted conformations (Table 1). Therefore, it could be rationalized that the turn-on voltages of C-4mTPE and $\mathrm{Si}-4 m \mathrm{TPE}$ would be decreased in comparison with those of other four molecules.

\subsection{Electroluminescence}

As a result of their good thermal stabilities and efficient light emission in the solid state, we fabricated non-doped OLED devices using these AIEgens as emitting layers with a configuration of indium tin oxide (ITO)/PEDOT: PSS $(30 \mathrm{~nm}) / \mathrm{EML}(30 \mathrm{~nm}) / \mathrm{TmPyPB}(50 \mathrm{~nm}) / \mathrm{Liq}(1 \mathrm{~nm}) / \mathrm{Al}$ $(100 \mathrm{~nm})$ by spin-coating, in which, the ITO was utilized as anode, PEDOT: PSS(ploy(3,4-enthylenedioxythiophene): poly(styrenesulfonate)) worked as the holeinjection layer, TmPyPB acted as the electron-transporting and hole-blocking layer, and Liq worked as the electrontransporting material, respectively. However, when using $\mathrm{C}-4 \mathrm{pTPE}$ as the emitting layer to fabricate OLED devices, its bad solubility makes it very difficult to be spin-coated. Thus, we did not get the EL data of C-4pTPE. The performance and EL data of the other five molecules are depicted and summarized in Figure 2 and S11 and Table 2. Devices $\mathrm{A} \sim \mathrm{E}$ emit bright sky blue $\mathrm{EL}$ in the range of $458 \sim 502$ $\mathrm{nm}$, which are close to the PL spectra of their amorphous thin films. This indicates that both the EL and PL spectra are originated from the same radiative decay of the singlet excitions. The OLED device E based on Si-4pTPE turned on at a voltage of $8.5 \mathrm{~V}$ and exhibited the best performance

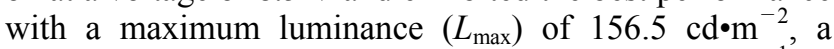
maximum current efficiency $\left(\eta_{\mathrm{C}, \max }\right)$ of $1.41 \mathrm{~cd} \bullet \mathrm{A}^{-1}$, a maximum power efficiency $\left(\eta_{\mathrm{p}, \max }\right)$ of $0.47 \mathrm{~lm} \cdot \mathrm{W}^{-1}$ and a maximum external quantum efficiency $\left(\eta_{\text {ext,max }}\right)$ of $0.62 \%$, respectively. For device $\mathrm{E}$ and $\mathrm{D}$ based on $\mathrm{Si}-4 p \mathrm{TPE}$ and $\mathrm{Si}-4 m \mathrm{TPE}$, the structure is more twisted for $\mathrm{Si}-4 m \mathrm{TPE}$ due to the meta-linkage, thus the emission of device D was blue-shifted by about $18 \mathrm{~nm}$. And for devices $\mathrm{E}$ and $\mathrm{C}$ based on $\mathrm{Si}-4 p$ TPE and $\mathrm{Si}-4$ triPE, the configuration length of Si-4triPE was a little shorter than that of Si- $4 p$ TPE due to the lack of one phenyl ring. Thus the emission of device $\mathrm{C}$ was blue-shifted by about $16 \mathrm{~nm}$. However, the performance of device C and D were not so good as device E. And the emissions of the AIEgens were all red-shifted in their nondoped OLED devices in comparison with those of their thin films.

Considering the good performance of device $\mathrm{E}$ based on $\mathrm{Si}-4 p$ TPE, we further fabricated the doped OLED device $\mathrm{F}$ through spin-coating with a configuration of ITO/PEDOT: PSS $(30 \mathrm{~nm}) / \mathrm{mCP}: \operatorname{Si}-4 p$ TPE $(90: 10,30 \mathrm{~nm}) / \mathrm{TmPyPB}$ $(50 \mathrm{~nm}) / \mathrm{Liq}(1 \mathrm{~nm}) / \mathrm{Al}(100 \mathrm{~nm})$, in order to further improve the device performance. Figure 2 shows the current characteristics, current efficiency, power efficiency and external quantum efficiency versus current density curves of the OLED device F, with the detail data listed in Table 2. The emission of device $F$ is in the blue region $\left(\lambda_{\max }=\right.$ $478 \mathrm{~nm}$ ), blue-shifted $18 \mathrm{~nm}$ in comparison with that of the nondoped device E. The maximum luminance $\left(L_{\max }\right)$, maximum current efficiency $\left(\eta_{\mathrm{C}, \max }\right)$, maximum power efficiency $\left(\eta_{\mathrm{p} \text {,max }}\right)$ and maximum external quantum efficiency $\left(\eta_{\text {ext,max }}\right)$ of device $\mathrm{F}$ all have considerable increases at $1730 \mathrm{~cd} \cdot \mathrm{m}^{-2}, 2.21 \mathrm{~cd} \cdot \mathrm{A}^{-1}, 0.77 \mathrm{~lm} \cdot \mathrm{W}^{-1}$ and $1.01 \%$, respectively, much better than those of device $\mathrm{E}$. 

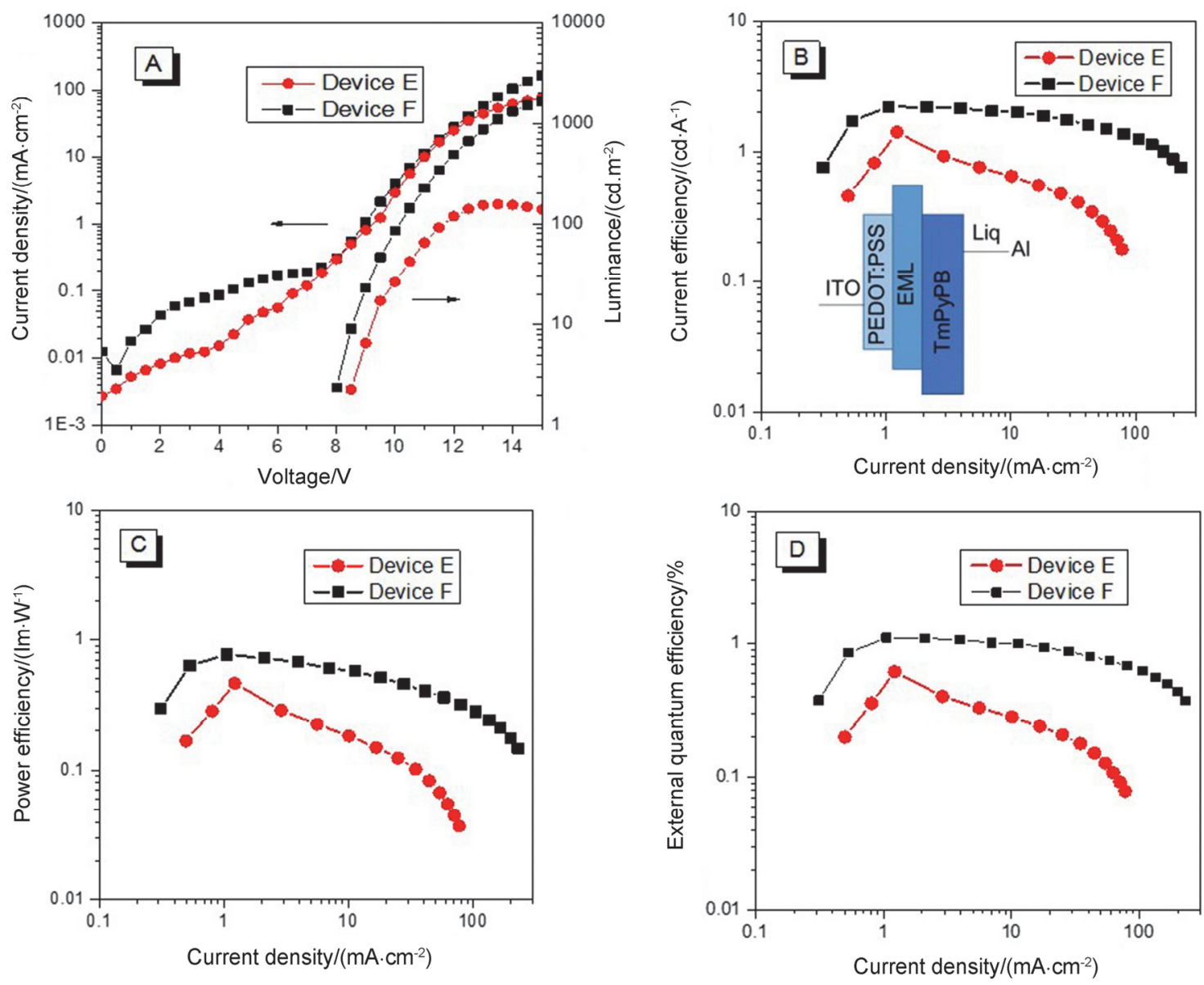

Figure 2 Changes in (A) current density and luminance with the applied voltage, (B) current efficiency with the current density. Inset: the simple configuration of the device, (C) Power efficiency with the current density, (D) External quantum efficiency with the current density. Device configuration: ITO/PEDOT:PSS(30 nm)/(Device E) Si-4pTPE (30 nm), (Device F) mCP:Si-4pTPE $(90: 10,30 \mathrm{~nm}) / \mathrm{TmPyPB}(50 \mathrm{~nm}) / \mathrm{Liq}(1 \mathrm{~nm}) / \mathrm{Al}(100 \mathrm{~nm})$

Table 2 EL performances of devices A $\sim$ F. Device configuration: ITO/PEDOT:PSS (30 nm)/(A) C-4triPE (30 nm) (B) C-4mTPE (30 nm) (C) Si-4triPE $(30 \mathrm{~nm})(\mathrm{D}) \mathrm{Si}-4 m$ TPE $(100 \mathrm{~nm})(\mathrm{E}) \mathrm{Si}-4 p \operatorname{TPE}(30 \mathrm{~nm})(\mathrm{F}) \mathrm{mCP}: \operatorname{Si}-4 p \operatorname{TPE}(90: 10,30 \mathrm{~nm}) / \mathrm{TmPyPB}(50 \mathrm{~nm}) / \mathrm{Liq}(1 \mathrm{~nm}) / \mathrm{Al}(100 \mathrm{~nm})$

\begin{tabular}{|c|c|c|c|c|c|c|c|}
\hline Device & $\lambda_{\mathrm{EL}} / \mathrm{nm}$ & $V_{\mathrm{on}} / \mathrm{V}$ & $L_{\max } /\left(\mathrm{cd} \cdot \mathrm{m}^{-2}\right)$ & $\eta_{\mathrm{P}, \max } /\left(\mathrm{lm} \cdot \mathrm{W}^{-1}\right)$ & $\eta_{\mathrm{C}, \max } /\left(\mathrm{cd} \cdot \mathrm{A}^{-1}\right)$ & $\eta_{\text {ext, } \max } / \%$ & $\operatorname{CIE}(x, y)$ \\
\hline A & 458 & 5.5 & 445.1 & 0.32 & 0.56 & 0.32 & $0.21,0.26$ \\
\hline B & 502 & 7.5 & 97.78 & 0.95 & 0.36 & 0.16 & $0.27,0.37$ \\
\hline $\mathrm{C}$ & 480 & 5.5 & 122.4 & 0.08 & 0.19 & 0.09 & $0.24,0.30$ \\
\hline D & 478 & 14.5 & 33.11 & 0.08 & 0.40 & 0.23 & $0.20,0.25$ \\
\hline E & 496 & 8.5 & 156.5 & 0.47 & 1.41 & 0.62 & $0.26,0.37$ \\
\hline $\mathrm{F}$ & 478 & 8 & 1730 & 0.77 & 2.21 & 1.01 & $0.21,0.29$ \\
\hline
\end{tabular}

Abbreviations: $V_{\mathrm{on}}=$ turn-on voltage at $1 \mathrm{~cd} \cdot \mathrm{m}^{-2}, L_{\max }=$ maximum luminance, $\eta_{\mathrm{P}, \max }, \eta_{\mathrm{C}, \max }$ and $\eta_{\mathrm{ext} \text { max }}=$ maximum power, current and external efficiencies, respectively. $\mathrm{CIE}=$ Commission International de l'Eclairage coordinates.

\section{Conclusion}

In summary, with aim to construct spin-coating AIEgens for blue OLED devices, six AIEgens of C-4triPE, C- $4 p$ TPE, C- $4 m$ TPE, Si-4triPE, Si- $4 p$ TPE and Si- $4 m$ TPE were synthesized, by utilizing tetraphenylmethane and tetraphenylsilane as the core. Through the adjustment of the linkage mode and the number of phenyl rotors to control the intramolecular conjugation, we can tune the emission light with $\lambda_{\max }$ from 448 to $492 \mathrm{~nm}$. When fabricated into OLED devices through spin-coating as the emitters,
Si-4pTPE in device $\mathrm{E}$ exhibited the best performance among the nondoped devices. Further utilized in doped OLED device F, even better performance was achieved, with a blue emission at $478 \mathrm{~nm}$ and $L_{\max }, \eta_{\mathrm{C}, \max }, \eta_{\mathrm{p}, \max }$, $\eta_{\text {ext,max }}$ at $1730 \mathrm{~cd} \bullet \mathrm{m}^{-2}, 2.21 \mathrm{~cd} \bullet \mathrm{A}^{-1}, 0.77 \mathrm{~lm} \cdot \mathrm{W}^{-1}, 1.01 \%$, respectively, while the CIE chromaticity coordinates of $(0.20,0.25)$.

\section{References}

[1] Tang, C. W.; VanSlyke, S. A. Appl. Phys. Lett. 1987, 51, 913.

[2] Ma, Y. G.; Zhang, H.; Shen, J. C.; Che, C. Synth. Met. 1998, 94, 245. 
[3] D'Andrade, B. W.; Forrest, S. R. Adv. Mater. 2004, 16, 1585.

[4] Li, J. Y.; Ma, C. W.; Tang, J. X.; Lee, C. S.; Lee, S. T. Chem. Mater. 2005, 17,615 .

[5] Li, J.; Liu, D.; Li, Y.; Lee, C. S.; Kwong, H.; Lee, S. Chem. Mater. 2005, 17, 1208.

[6] Braun, D.; Heeger, A. J. Appl. Phys. Lett. 1991, 58, 1982.

[7] Wu, W. S.; Inbasekaran, M.; Hudack, M.; Welsh, D.; Yu, W. L.; Cheng, Y.; Wang, C.; Kram, S.; Tacey, M.; Bernius, M.; Fletcher, R.; Kiszka, K.; Munger, S.; O’Brien, J. Microelectron. J. 2004, 35, 343.

[8] Bernius, M. T.; Inbasekaran, M.; O’Brien, J. J.; Wu, W. Adv. Mater. 2000, 12, 1737 .

[9] (a) Förster, T.; Kasper, K. Z. Phys. Chem.(Muenchen, Ger), 1954, 1, 275; (b) Jakubiak, R.; Collision, C. J.; Wan, W. C.; Rothberg, L. J. Phys. Chem. A 1999, 103, 2394. (c) Lemmer, U.; Heun, S.; Mahrt, R. F.; Schert, U.; Hopmeier, M.; Siegner, U.; Göbel, E. O.; Müllen, K.; Bassler, H. Chem. Phys. Lett. 1995, 240, 373.

[10] (a) Luo, J.; Xie, Z.; Lam, J. W. Y.; Cheng, L.; Chen, H.; Qiu, C.; Kwok, H. S.; Zhan, X.; Liu, Y.; Zhu, D.; Tang, B. Z. Chem. Commun. 2001, 1740; (b) Qian, L. J.; Tong, B.; Zhi, J. G.; Yang, F.; Shen, J. B.; Shi, J. B.; Dong, Y. P. Acta Chim. Sinica 2008, 66, 1134 (in Chinese). (钱立军, 佟斌, 支俊格, 杨帆, 申进波, 石建兵, 董宇 平, 化学学报, 2008, 66, 1134.); (c) Xun, Z. Q.; Tang, H. Y.; Zeng, Y.; Chen, J. P.; Yu, T. J.; Zhang, X. H.; Li, Y. Acta Chim. Sinica 2015, 73, 819 (in Chinese). (寻知庆, 唐海云，曾毅，陈金平，于天 君, 张小辉, 李嫕, 化学学报, 2015, 73, 819.)

[11] (a) Yang, J.; Huang, J.; Li, Q.; Li, Z. J. Mater. Chem. C 2016, 4, 2663. (b) Li, Z. Sci. China Chem. 2015, 58, 969. (c) Li, Q.; Li, Z. Sci. China Chem. 2015, 58, 1800. (d) Zhang, X.; Zhang, X.; Yang, B.; Wei, Y. Chin. J. Polym. Sci. 2014, 32, 1479. (e) Wang, R.; Yuan, W.; Zhu, X. Chin. J. Polym. Sci. 2015, 33, 680. (f) Wu, W.; Tang, R.; Li, Q.; Li, Z. Chem. Soc. Rev. 2015, 44, 3997.
[12] (a) Tung, Y. J.; Nago, T.; Hack, M.; Brown, J.; Koide, N.; Nagara, Y.; Kato, Y.; Ito, H. Dig. Tech. Pap.-Soc. Inf. Disp. Int. Symp 2004, 35, 48. (b) Lee, M. T.; Liao, C. H.; Tsai, C. H.; Chen, C. H. Adv. Mater 2005, 17, 2493. (c) Lee, S. J.; Park, J. S.; Yoon, K. J.; Kim, Y. I.; Jin, S. H.; Kang, S. K.; Gal, Y. S.; Kang, S.; Lee, J. Y.; Kang, J. W.; Lee, S. H.; Park, H. D.; Kim, J. J. Adv. Funct. Mater. 2008, 18, 3922. (d) Lai, M. Y.; Chen, C. H.; Huang, W. S.; Lin, J. T.; Ke, T. H.; Chen, L. Y.; Tsai, M. H.; Wu, C. C. Angew. Chem., Int. Ed. 2008, 47, 581. (e) Chen, C. H.; Huang, W. S.; Lai, M. Y.; Tsao, W. C.; Lin, J. T.; Wu, Y. H.; Ke, T. H.; Chen, L. Y.; Wu, C. C. Adv. Funct. Mater. 2009, 19 2661. (f) Zheng, C. J.; Wang, J.; Ye, J.; Lo, M. F.; Liu, X. K.; Fung, M. K.; Zhang, X. H.; Lee, C. S. Adv. Mater. 2013, 25, 2205.

[13] (a) Farinola, G. M.; Ragni, R. Chem. Soc. Rev. 2011, 40, 3467. (b) Gather, M. C.; Köhnen, A.; Meerholz, K. Adv. Mater. 2011, 23, 233.

[14] (a) Kang, D. M.; Kang, J. W.; Park, J. W.; Jung, S. O.; Lee, S. H.; Park, H. D.; Kim, Y. H.; Shun, S. C.; Kim, J. J.; Kwon, S. K. Adv. Mater. 2008, 20, 2003. (b) Park, T. J.; Jeon, W. S.; Park, J. J.; Kim, S. Y.; Lee, Y. K.; Jang, J.; Kwon, J. H.; Pode, R. Appl. Phys. Lett. 2008, 92, 113308 .

[15] (a) Yang, J.; Huang, J.; Sun, N.; Peng, Q.; Li, Q. Q.; Ma, D. G.; Li, Z. Chem. Eur. J. 2015, 21, 1. (b) Huang, J.; Tang, R. L.; Zhang, T.; Li, Q. Q.; Yu, G.; Xie, S. Y.; Liu, Y. Q.; Ye, S. H.; Qin, J. G.; Li, Z. Chem. Eur. J. 2014, 20, 5317. (c) Huang, J.; Sun, N.; Dong, Y.; Tang, R.; Lu, P.; Cai, P.; Li, Q.; Ma, D.; Qin, J.; Li, Z. Adv. Funct. Mater 2013, 23, 2329. (d) Huang, J.; Sun, N.; Yang, J.; Tang, R.; Li, Q.; Ma, D.; Li, Z. Adv. Funct. Mater. 2014, 24, 7645. (e) Huang, J.; Yang, M.; Yang, J.; Tang, R.; Ye, S.; Li, Q.; Li, Z. Org. Chem. Front. 2015, $2,1608$.

[16] Wang, S. J.; Oldham Jr., W. J.; Hudack Jr., R. A.; Bazan, G. C. J. Am. Chem. Soc. 2000, 122, 5695.

[17] Parker, C. A.; Rees, W. T. Analyst 1960, 85, 587. 